\title{
MICROCRÉDITO COMO FORMA DE DESENVOLVIMENTO LOCAL ATRAVÉS DOS BANCOS COMUNITÁRIOS: UMA ANÁLISE DO BANCO PALMAS
}

\author{
MICROCREDIT AS A FORM OF LOCAL DEVELOPMENT TROUGH \\ THE COMMUNITY BANKS: AN ANALYSIS OF PALMAS BANK
}

Carolina Barbosa Mesquita de Andrade ${ }^{1}$

Karla Rafaela Nascimento da Silva ${ }^{2}$

Rosaura Maria Barbosa Mesquita Neiva ${ }^{3}$

Mestranda em Gestão Pública pela Universidade Federal de Pernambuco; especialista em Intervenções Psicossociais com Grupos em Situação de Risco e Vulnerabilidade pela Faculdade Frassinete do Recife; especialista em Gestão de Pessoas pela Faculdade de Teologia Integrada; e Bacharel em Psicologia pela Faculdade Frassinete do Recife. Servidora da Universidade Federal Rural de Pernambuco, no cargo de Técnico-administrativo

2

Mestranda em Gestão Pública pela Universidade Federal de Pernambuco; especialista em Gestão com Pessoas pela Universidade de Pernambuco; e Bacharel em Administração pela Universidade de Pernambuco. Servidora da Universidade Federal de Pernambuco, no cargo de Técnico-administrativo.

3

Mestranda em Gestão Pública pela Universidade Federa de Pernambuco; especialista em Administração com Ênfase em Marketing pela Universidade Federal Rural de Pernambuco; e Bacharel em Comunicação Visual pela Universidade Federal de Pernambuco. Servidora da Universidade Federal Rural de Pernambuco, no cargo de Técnico-administrativo.
RESUMO: Este artigo busca demonstrar o desenvolvimento local através das ações dos bancos comunitários de desenvolvimento. Para tanto, foram utilizados dados de um dos maiores exemplos de Banco Comunitário de Desenvolvimento - BCD, o Banco Palmas. A finalidade do artigo é analisar a viabilidade desses bancos para a comunidade no qual está inserido, utilizando dados concretos coletados no banco em estudo. Neste sentido, foi utilizada como metodologia a pesquisa bibliográfica, aliada aos dados estatísticos fornecidos pelo próprio Banco Palmas e o site do Atlas Brasil. Através dos dados coletados foi possível demonstrar o desenvolvimento da Comunidade Palmeiras e o crescimento do volume dos serviços ofertados pelo banco no período de 2000 a 2013. Desta forma foi possível concluir que a oferta de créditos à população de baixa renda, através de bancos comunitários, vem como alternativa econômica e social de desenvolvimento e aumento da qualidade de vida.

palavras-chave: Microcrédito, Banco Comunitário de Desenvolvimento, desenvolvimento local, Banco Palmas.

AbSTRACт: This article seeks to demonstrate local development through the actions of community development banks. For that, data from one of the largest examples of the Community Development Bank - BCD, Banco Palmas was used. The purpose of the article is to analyze the viability of these banks to the community in which it is inserted, using concrete data collected in the bank under study. In this sense, the bibliographical research was used as a methodology, together with the statistical data provided by Banco Palmas itself and the Atlas Brasil website. Through the collected data it was possible to demonstrate the development of the Palmeiras Community and the growth in the volume of services offered by the bank in the period from 2000 to 2013. In this way it was possible to conclude that the offer of credits to the low income population, through community banks, comes as an economic and social alternative of development and an increase in the quality of life.

KEYWORDs: Microcredit, Community Development Bank, local development, Palmas Bank. 


\section{INTRODUÇÃO}

Os princípios capitalistas disseminados de forma global acentuaram as diferenças entre ricos e pobres, trouxeram a produção de riquezas e incentivaram na sociedade a sede do consumo, mas deixaram à margem aqueles que não se enquadram nesses padrões capitalistas.

A mudança na forma de trabalho trazida pela Revolução Industrial, acentuada pelo desenvolvimento tecnológico ocorrido na indústria, o qual foi chamado de segunda Revolução Industrial, a partir da segunda metade do século XIX, onde a máquina passa a substituir a mão de obra humana, acarretou um crescente número de desempregados, ao tempo que elevou a produção de produtos e o estímulo ao consumo. Essa massa da sociedade desempregada e sem apoio financeiro por parte dos governos e instituições privadas aumentava e demandava um olhar especial, uma vez que eram apenas pessoas de baixa renda, mas com grande capacidade de produzir e gerar crédito, tornando-se trabalhadores informais em virtude da necessidade de sobrevivência.

A nossa visão da economia ainda está centrada na visão fabril do séc. XX. Mas o setores emergentes da economia não são fábricas, são redes de saúde, sistemas articulados de educação, de pesquisa e organização do conhecimento, atividades culturais e assim por diante. (DOWBOR, 2012).

A indústria microfinanceira nasceu da necessidade de atender essa faixa de empregados informais, micro e pequenas empresas que não tinham instituições financeiras que os atendessem nos momentos que precisavam de ajuda para manter, crescer ou até mesmo reformar seus pequenos negócios ou atividades de trabalho. Por não existir um consenso na literatura específica, segundo Barone e Sader (2008), ressalta-se a diferença entre Microfinanças e Microcrédito, apesar de diversos pesquisadores os tratarem como sinônimos.

Segundo Coelho (2006) apud Soares e Sobrinho (2008), "...microfinanças abrange a provisão de serviços financeiros voltados para os pobres, lidando com depósitos e empréstimos de pequena monta, independentemente da possível destinação do crédito tomado."

Seguindo o entendimento de formuladores de políticas dentro do Governo Brasileiro (principalmente Ministério da Fazenda e Ministério do Trabalho e Emprego) e o consenso de especialistas do Banco Mundial, compilado por Christen (2003), o termo microfinanças, portanto, refere-se à prestação de serviços financeiros adequados e sustentáveis para população de baixa renda, tradicionalmente excluída do sistema financeiro tradicional, com utilização de produtos, processos e gestão diferenciados. (SOARES E SOBRINHO, 2008)

Já o termo microcrédito, tem um caráter menos abrangente, é a oferta de todos os serviços financeiros, no contexto das microfinanças, exclusivamente para pessoas físicas e jurídicas microempreendedoras, excluindo-se o crédito para consumo, sendo conceituado como principal atividade do setor de Microfinanças em virtude do seu caráter de superação da pobreza e geração de renda. 
Neste artigo, será analisado o Microcrédito, principalmente por seu caráter gerador de renda e desenvolvimento local, através das ações do Banco Palmas, como exemplo de Banco Comunitário de Desenvolvimento.

\section{MICROCRÉDITO}

A principal característica do microcrédito é a ausência de garantias reais, diferentemente das exigências dos bancos tradicionais. $\mathrm{O}$ microcrédito trabalha com duas formas de garantias: a garantia através de um fiador individual e a garantia através do aval solidário de pessoas da própria comunidade, que garantem mutuamente os créditos concedidos. Este último tipo é um processo de busca pelo bom pagador para constituir uma rede de apoio, porque se sabe que a falta de pagamento de um faz com que os outros respondam pelo crédito.

Outra característica importante do microcrédito produtivo orientado é a relação direta entre o tomador de crédito e as instituições, onde eles são procurados e analisados por agentes de créditos, a quem compete realizar uma análise socioeconômica do empreendedor, bem como a potencialidade de desenvolvimento da atividade, a fim de subsidiar a liberação do crédito.

O principal objetivo da política de MPO (Microcrédito Produtivo Orientado) é a constituição de um sistema institucional capaz de incluir financeiramente uma miríade de microempresários por meio de uma metodologia que busca não só monitorar estes pequenos negócios, mas, principalmente, difundir uma cultura de educação financeira a partir do crédito produtivo assistido (souzA, p. 29, 2018)

Diante do exposto, percebe-se que a figura do agente de crédito na metodologia já explicada é essencial para que todo o sistema funcione. Tais agentes continuam acompanhando e orientando os pequenos empreendedores durante todo o período do contrato, proporcionando assistência em relação ao planejamento e desenvolvimento do empreendimento.

As liberações dos créditos possuem uma natureza mais ágil e menos burocratizada, em relação aos procedimentos dos bancos tradicionais. Yunus e Jolis (2000) apud Souza (2018) corroboram que "é o trabalho dos agentes de crédito que tem assegurado níveis de inadimplência relativamente baixos para as instituições que ofertam serviços microfinanceiros".

Com a introduçãono Brasil do Programa Nacional do Microcrédito Produtivo Orientado (PNMPO), no ano de 2005, cujo qual enfatizou a importância do apoio técnico às instituições ofertantes habilitadas, o debate sobre o papel dos agentes de crédito tomou proporções maiores. Tal fato favoreceu a introdução, em 2009, dessa profissão no Catálogo Brasileiro de Ocupações do Ministério do Trabalho e Emprego (CBO).

Faz-se importante agora uma visão geral sobre a história do microcrédito no mundo e, mais especificamente, no Brasil. Isso ajudará 
a refletirmos melhor sobre essa temática, bem como, a entender como esse segmento serve de alavanca para o desenvolvimento local, dentre outras formas, através dos bancos comunitários de desenvolvimento.

\subsection{MICROCRÉDITO NO MUNDO}

No mundo já houve várias experiências bem-sucedidas dos bancos sociais, ou entidades similares, implantadas nos países como Bangladesh com o Grameen Bank, Indonésia, Bolívia e Peru.

$O$ primeiro fato que se pode considerar como o surgimento do microcrédito ocorreu no sul da Alemanha em 1846, quando o pastor Raiffeinsen cedeu farinha de trigo para um grupo de fazendeiros endividados com agiotas, em virtude de um rigoroso inverno, para que pudessem fabricar e comercializar pão. Com muito trabalho e o passar do tempo, transformou-se em uma cooperativa de crédito para a população pobre.

A primeira cooperativa de crédito fundada nas Américas surgiu em 1900 em Quebec, Canadá, fundada pelo jornalista Alphonse Desjardins, a "Caisse Populaire de Lévis", que sensibilizado com a condenação de pessoas em virtude do não pagamento de empréstimos com altas taxas de juros, começou a buscar alternativas para essas situações. Porém, apesar de já terem existido diversas experiências de microcrédito em vários países do mundo, foi só em 1976 com a criação do Banco Grameen pelo professor Muhammad Yunnus, em Bangladesh, que este tipo de ação financeira ganhou visibilidade e reconhecimento como sendo uma possibilidade real de desenvolvimento social e econômico para regiões subdesenvolvidas ou em desenvolvimento.

Como professor de economia da Universidade de Chittagong, Yunnus observou que a população de baixa renda do entorno da universidade não possuía acesso aos créditos dos bancos comerciais, e iniciou um trabalho de concessão de empréstimos a uma pequena parcela daquela população, começando com o empréstimo de 27 dólares a 42 pessoas. Yunus se responsabilizou pelo que os bancos não podiam fazer, pois estavam presos a uma grande quantidade de garantias e assinaturas. Ele observou como os bancos trabalhavam e fez exatamente o contrário. Assim, foi criado o Grameen Bank ou "banco da aldeia", onde os próprios clientes são os donos, gerenciando e participando de decisões, sendo considerado o primeiro exemplo de banco comunitário.

Conhecido no mundo todo como "o banqueiro dos pobres", Yunnus ampliou o conceito de microcrédito, fazendo empréstimos sem garantias ou papéis a pessoas muito pobres, principalmente mulheres, que não tinham acesso a bancos ou a outras formas de empréstimos. Ao conseguir provar que as pessoas eram merecedoras de confiança e que destinavam seus empréstimos a atividades produtivas, Yunnus conseguiu financiamentos e doações de empresas e bancos privados e internacionais para a criação do Banco Grameen. Ganhador do prêmio Nobel da Paz em 2006, o exemplo do Banco Grameen trouxe o Microcrédito para o centro das possibilidades de desenvolvimento 
social. A ideia se espalhou por quase todos os países do mundo, incluindo países desenvolvidos e industrializados.

O Grameen Bank tem mais de 8,5 milhões de mutuários, 97\% dos quais são mulheres, e desembolsa mais de 1,5 bilhões de dólares por ano, com uma taxa de inadimplência de apenas 3\%. (FONTE: Revista Época, o9/06/2013).

\subsection{MICROCRÉDITO NO BRASIL}

No Brasil e na América do Sul, a primeira ação de concessão de crédito e orientação gerencial para pequenos empreendedores ocorreu em 1973 com a criação da União Nordestina de Assistência a Pequenas Organizações, que ficou conhecida como Programa UNO, nas cidades de Recife e Salvador. A UNO era uma Associação Civil, sem fins lucrativos, que concedeu créditos e capacitação a trabalhadores de baixa renda do setor informal. O projeto foi uma iniciativa e contou com a assistência técnica da Accion Internacional, e com a participação de bancos e empresas de Pernambuco e da Bahia.

Segundo Valdi de Araújo Dantas, ex-funcionário da UNO: "A Accion fazia um trabalho assistencial de apoio às comunidades periféricas do Grande Recife e percebeu que a principal estratégia de sobrevivência dessa população era montar pequenos negócios por conta própria. Encomendaram uma pesquisa para a pós-graduação em economia da UFPE, com pequenos empreendedores, e a pesquisa indicou que a maior necessidade deles era crédito para capital de giro e orientação gerencial". (FONTE: Revista Abcred: Abril-2018).

Com base nos resultados foi criado o Programa UNO, que contou com recursos de doações internacionais e com uma linha de crédito do governo federal. O Programa UNO funcionou de 1973 a 1991. Porém, a prática de juros subsidiados comprometeu a sustentabilidade da organização quando os recursos externos e do governo federal começaram a escassear.

No Brasil, as Instituições de Microfinanças surgiram e se desenvolveram através de incentivos de entidades de cooperação internacionais, a exemplo da UNO, que priorizavam resultados sociais, e posteriormente, o Estado passa a conduzir e orientar a atuação das instituições através da regulamentação das leis e normas editadas, tornando-se uma política de Estado.

Segundo Keynes (Keynes apud Reboredo, 2016) “Também cremos que uma socialização bastante ampla do investimento se revelará como o único meio capaz de garantir, pelo menos aproximadamente, o pleno emprego" (Fonte: JusBrasil), o Estado precisa intervir nos problemas econômicos da sociedade, ofertando recursos e meios para superá-los, garantindo assim o direito de renda a todo cidadão. A taxa de desemprego e quantos milhões de pessoas estão desempregadas representam, de forma mais fidedigna, a realidade econômica e social de um país (Sicsu, 2007). 
A Lei 10.735/2003 instituiu a destinação compulsória de 2\% dos depósitos à vista dos bancos para operações de microcrédito, a fim de garantir mais recursos. Tais recursos somados aos provenientes do Fundo de Amparo ao Trabalhador (FAT), orçamento da União, dos fundos constitucionais de financiamento do Norte, do Nordeste e do Centro-Oeste, de que trata a alínea "c" do inciso I do caput do art. 159 da Constituição Federal, aplicáveis no âmbito de suas regiões, posteriormente foram destinados ao Programa Nacional de Microcrédito Produtivo Orientado - PNMPO, instituído pela Lei no 11.110, de 25 de abril de 2005 .

Essa Lei implantou e legalizou o novo conceito de "microcrédito produtivo orientado", voltado exclusivamente para o atendimento das necessidades financeiras de pessoas físicas e jurídicas empreendedoras de atividades produtivas de pequeno porte, utilizando metodologia baseada no relacionamento direto com os empreendedores no local onde é executada a atividade econômica. Segundo Bittencourt (2005, 24), o objetivo do PNMPO era ampliar o acesso aos empreendedores de atividades produtivas de pequeno porte ao crédito produtivo orientado, direcionando-os para geração de trabalho e renda. A intenção com a publicação da Lei era o fortalecimento institucional e a disponibilização de recursos para os programas de microcréditos.

Conforme dados do Banco Central do Brasil quando se comparou os dados de novas operações de microcrédito produtivo orientado e de concessões ocorridas em 2007, com as ocorridas em 2005 desde a criação da PNMPO, obteve-se um crescimento de 52,42\% na quantidade de operações, e de $82,68 \%$ no que se refere ao índice do volume de crédito concedido.

Tais regulamentações trouxeram alguns entraves na expansão das liberações de microcréditos, apesar de ainda gerar o percentual de crescimento demonstrado, confirmando assim que o PNMPO é válido, precisando apenas de ajustes na regulamentação (BCB, 2009). Sua primeira alteração é feita pela Lei $13.636 / 2018$, que traz entre as principais alterações, o aumento, de $\mathrm{R} \$ 120$ mil para até $\mathrm{R} \$ 200$ mil, do limite de renda ou receita bruta anual para enquadramento de pessoas físicas e jurídicas. A intenção é agilizar o empréstimo e aumentar o universo de beneficiados, reajustando o valor máximo que estava congelado desde 2008.

O PNMPO pode ser operado por cooperativas, agências de fomento, bancos de desenvolvimento, Sociedades de Crédito ao Microempreendedor e à Empresa de Pequeno Porte- SCMEPP, CEF, BNDES, organizações da sociedade civil de interesse público- OSCIPS. 


\section{MICROCRÉDITO COMO DESENVOLVIMENTO ECONÔMICO E SOCIAL}

O desenvolvimento econômico de um país está ligado ao aumento do Produto Interno Bruto - PIB e ao crescimento do Índice de Desenvolvimento Humano-IDH. A política de microcréditos vem possibilitar um aumento na produção de bens e serviços a pequenos e microempreendedores, além de trazer crescimento profissional através das capacitações e orientações que caracterizam a PNMPO, tornando-se assim uma importante ferramenta de inclusão financeira no combate à pobreza e ao desemprego, assumindo um importante papel no desenvolvimento econômico e social. Ações como estas acabam afetando diretamente a qualidade de vida da comunidade.

A sociedade moderna e globalizante, em constante modificações na suas estruturas econômicas, tecnológicas e de formas de produção de bens e serviços, vem sofrendo com a diminuição de oferta de empregos formais. A solução para grande parte da classe da base da pirâmide social é a busca pelo trabalho informal, de caráter empreendedor. Muitas dessas tentativas esbarram em obstáculos como a falta de visão empresarial, de capital de giro, de visão de gestão de negócios e principalmente a falta da possibilidade de buscar crédito junto aos bancos formais. É para esse nicho de mercado, de faixa da sociedade que o microcrédito vem trazer a possibilidade de desenvolvimento econômico e social.

Tal importância foi percebida e vem sendo valorizada pelos governos federais, estaduais e municipais com a implantação de leis e regulamentos que visam ampliar e disseminar a política de microcrédito por representar importante instrumento de inclusão social e desenvolvimento.

Para Barone (2002, p.11) o impacto social do microcrédito é reconhecidamente positivo, resultando em melhores condições habitacionais de saúde e alimentar para as famílias usuárias. Além de contribuir para o resgate da cidadania dos tomadores de crédito, com o respectivo fortalecimento da dignidade, a elevação da autoestima e a inclusão em patamares de educação e consumo superiores.

\section{BANCOS COMUNITÁRIOS DE DESENVOLVIMENTO}

Com o objetivo de diminuir os custos de operações bancárias e incluir grande parte da população de baixa renda com um alto grau de vulnerabilidade social no sistema financeiro, foram criados os Bancos Comunitários de Desenvolvimento (BCD). De acordo com o Instituto Banco Palmas de Desenvolvimento e Socioeconomia Solidária, são serviços solidários em rede, de natureza associativa e comunitária, voltados para a geração de trabalho e renda, tendo por base os princípios da Economia Solidária, sendo um tipo de garantia solidária para uma comunidade que necessita de microcréditos. 
Segundo Carmona e Rezende (2014), a atuação do banco se dá de forma integrada com a produção e o consumo local, pois é formulado a partir de linhas de crédito produtivo e de consumo, levando em consideração critérios de análise de crédito que contemple a realidade local. O uso da moeda social juntamente com a oferta de crédito para a promoção de atividades econômicas tem a função de centralizar nas comunidades a produção e o consumo local, afastando seus moradores dos grandes centros desenvolvidos.

Cabe esclarecer aqui, que o Instituto Banco Palmas de Desenvolvimento e Socioeconomia Solidária foi criado em 2003 pelos moradores do Conjunto Palmeiras para difundir a tecnologia social do Banco Palmas.

Os Bancos de Desenvolvimento fazem parte da rede operacional do PNMPO, sendo classificados com Agentes de Intermediação (AGI). Além desta categoria, a rede é composta também pelas Instituições Financeiras Operadoras (IFO), que são as instituições financeiras que operam os recursos do FAT (Banco do Brasil, Caixa Econômica Federal, Banco do Nordeste, Banco da Amazônia e Banco Nacional de Desenvolvimento Social-BNDES), e aquelas instituições que operam a parcela dos recursos de depósitos à vista (bancos comerciais, os bancos múltiplos com carteira comercial e os bancos oficiais) e pelas Instituições de Microcrédito Produtivo e Orientado (Impo), que são as cooperativas de crédito singulares, as agências de fomento (AF), de que trata a Medida Provisória n⿳0 2.192-70, de 24 de agosto de 2001, as sociedades de crédito ao microempreendedor, de que trata a Lei $\mathrm{n}^{0}$ 10.194, de 14 de fevereiro de 2001 e as Organizações da Sociedade Civil de Interesse Público (Oscips), de que trata a Lei no 9.790, de 23 de março de 1999.

O Ministério do Trabalho e Emprego através da Secretaria Nacional de Economia Solidária (SENAES), em parceria com a Fundação Banco do Brasil, iniciou um projeto de expansão de bancos comunitários por diversas localidades com baixo índice de desenvolvimento humano (IDH). Essa parceria veio para consolidar o desenvolvimento dos bancos comunitários de desenvolvimento, promovendo emprego e renda e na criação da Rede Brasileira de Bancos Comunitários de Desenvolvimento. (SANTOS APUd valérIo, 2011).

A partir do mapa 1, pode-se observar que no Brasil existem BCD em vários estados, sendo o Banco Palmas, o primeiro e um dos mais conhecidos, fundado em 1998, no conjunto Palmeiras em Fortaleza/CE. 


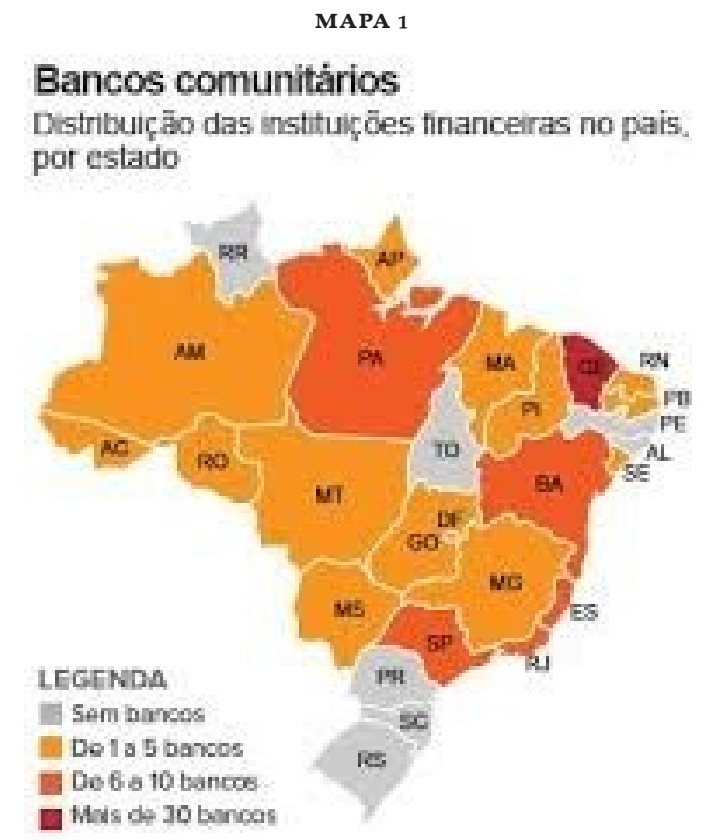

FONTE: Rede Brasileira de Bancos Comunitários

Os BCDs trabalham em conjunto com o poder público e com um banco público, que atua como um correspondente bancário. Essa parceria não é indispensável para o funcionamento dos BCDs, pois esses podem operar sem o auxílio de bancos oficiais, elaborando programas de gestão de créditos e moedas oficiais circulantes. A opção de atuar em conjunto com bancos oficiais é da comunidade em que o BCD atua, com objetivo de levar para comunidades mais excluídas, serviços bancários que antes só eram possíveis em bancos convencionais. Mas, para que essa parceria dê certo, tanto o poder público quanto o bancos que dão todo suporte, maquinário e tecnologia, devem entender que os BCDs devem manter sua autonomia.

Todos os BCDs que integram a Rede Brasileira de Bancos Comunitários de Desenvolvimento estão garantidos por um "selo de certificação" que organiza e unifica todos os Bancos, em processos éticos, estruturas e regras gerais que precisam ser seguidas por todos os BCDs, porém cada um tem liberdade para se organizar de forma local.

Os Bancos Comunitários de Desenvolvimento nascem dentro de uma comunidade caracterizada pela desigualdade social e exclusão e toda comunidade é a própria gestora e dona do Banco.

Distinguindo-se das práticas de microcrédito convencionais, que estão orientadas para a pessoa ou para a organização individual, os BCDs preocupam-se com o território ao qual pertencem, seja ele uma comunidade, um bairro ou um pequeno município. Nesse sentido, os BCDs procuram investir simultaneamente na capacidade de produção, de geração de serviços e de consumo territorial. Para tanto, eles financiam e orientam a construção de empreendimentos sócio-produtivos e de prestação de serviços locais, bem como, o próprio consumo local". (FRANÇA FILHO, 2013, p.85) 
Os BCDs trabalham com quatro eixos de ações: fundo de crédito solidário, moeda social circulante, estratégia de comercialização local e capacitação em economia solidária. Operam com duas linhas de crédito, que são o real e a moeda local ou moeda social circulante, já mencionada, criada para o uso dentro da comunidade. Essa linha de crédito serve para o consumo e produção local, como objetivo de promover o desenvolvimento da comunidade.

Neste último dia 20 de janeiro de 2018 os Bancos Comunitários de Desenvolvimento do Brasil fizeram 20 anos de existência, e com ele o Banco Palmas, que foi o primeiro banco da categoria. Em 2008, a quantidade de BCDs no Brasil já era de 37, e em 2018 já chegam a marca de 113 bancos distribuídos em 20 estados e 90 municípios, da seguinte forma, conforme o quadro abaixo:

QUADro 1 - Tabela de Banco Comunitário de Desenvolvimento - BCD

\begin{tabular}{|c|c|c|}
\hline REGIÃO & ESTADO & QUANTIDADE DE BCD'S \\
\hline \multirow{5}{*}{ Norte } & Pará & 12 (doze) \\
\hline & Acre & 2 (dois) \\
\hline & Amapá & 2 (dois) \\
\hline & Roraima & 1 (um) \\
\hline & Amazonas & 9 (nove) \\
\hline \multirow{7}{*}{ Nordeste } & Bahia & 8 (oito) \\
\hline & Sergipe & 1 (um) \\
\hline & Paraiba & 2 (dois) \\
\hline & Rio Grande fo Norte & 1 (um) \\
\hline & Piauí & 2 (dois) \\
\hline & Maranhão & 1 (um) \\
\hline & Ceará & 36 (trinta e seis) \\
\hline \multirow{4}{*}{ Centro- Oeste } & Distrito Federal & 3 (três) \\
\hline & Goias & 1 (um) \\
\hline & Mato Grosso fo Sul & 3 (três) \\
\hline & Mato Grosso & 3 (três) \\
\hline \multirow{4}{*}{ Sudeste } & Espírito Santo & 10 (dez) \\
\hline & São Paulo & 7 (sete) \\
\hline & Rio De Janeiro & 6 (seis) \\
\hline & Minas Gerais & 3 (três) \\
\hline
\end{tabular}

FONTE: Instituto Palmas -Elaborado pelas autoras

\subsection{BANCO PALMAS E A COMUNIDADE PALMEIRAS}

A Comunidade Palmeiras, no Ceará, foi formada, inicialmente, por pescadores transferidos da faixa litorânea para uma região de periferia de Fortaleza, em 1973. Os primeiros pescadores foram chegando e construindo seus barracos, sem nenhum projeto de urbanização por parte da Prefeitura de Fortaleza, sem saneamento básico, água tratada ou escolas. A população que ali habitava era extremamente pobre e sem nenhuma perspectiva de melhora de vida. 
O Conjunto Palmeiras, como é chamado, teve seu crescimento e desenvolvimento ligado à Associação dos Moradores do Conjunto Palmeiras (ASMOCONP), que posteriormente, em 1998, fundou um banco comunitário e solidário, o Banco Palmas. Através de mobilizações dos moradores e parcerias, a ASMOCONP foi aos poucos construindo o bairro. O objetivo de um banco comunitário não é a obtenção de lucros, como acontece em bancos privados, seus objetivos são trazer crescimento profissional para as pessoas e fomentar o desenvolvimento econômico da comunidade que decidiu implantá-lo e que são seus proprietários. É claro que os moradores da comunidade, sendo os donos e também os usuários dos bancos comunitários, irão trabalhar e se empenhar para que eles se desenvolvam e aumente seus recursos que serão usados como investimentos para novos projetos e manutenção dos que já existem.

Em 2003, a mesma Associação de moradores que criou o Banco Palmas cria o Instituto Palmas de Desenvolvimento e Socioeconomia solidária, uma OSCIP (Organização da Sociedade Civil de Interesse Público) de Microcrédito, que tem os objetivos de propagar a tecnologia do Banco Palmas, apoiando a criação de outros Bancos Comunitários no Brasil, integrando-os em rede. A Secretaria Nacional de Economia Solidária, do Ministério do Trabalho, em 2005 firmou uma parceria com o Instituto Palmas, passando a apoiar suas diversificadas atividades.

O principal serviço oferecido pelo Banco Palmas é o microcrédito tanto para o consumo quanto para a produção. O crédito para a produção é dado em reais e pretende melhorar as redes de relacionamento entre os produtores e consumidores. Já o crédito para o consumo é concedido em Palmas, a moeda social oficial do banco, com o objetivo de estimular o consumo e desenvolvimento local, e que é indexada ao real. O Banco conta com uma linha de microcrédito alternativo, instrumentos de incentivo ao consumo local e novas formas de comercialização como feiras e lojas solidárias.

Analisando no gráfico 1 os dados extraídos do site oficial do Banco Palmas, referente aos valores emprestados pelo banco na forma de crédito produtivo, no período de 2007 a abril de 2013, temos um aumento na ordem de $261,5 \%$ em 2008, 97,45\% em 2009 e um decréscimo de -0,48\% em 2010. Porém, a partir de 2011, podemos observar um grande crescimento nos valores brutos, perfazendo um percentual de aumento na ordem de $373,5 \%$, e o crescimento permanece com o percentual de $118,17 \%$ em 2012. Considerando que os dados de 2013 informados correspondem apenas ao primeiro trimestre do ano, e que superam os valores do primeiro trimestre de $2012 \mathrm{em} \mathrm{9,08 \% ,} \mathrm{podemos}$ concluir que o ano de 2013 superou a marca de valores do ano anterior. 
GRÁFICO

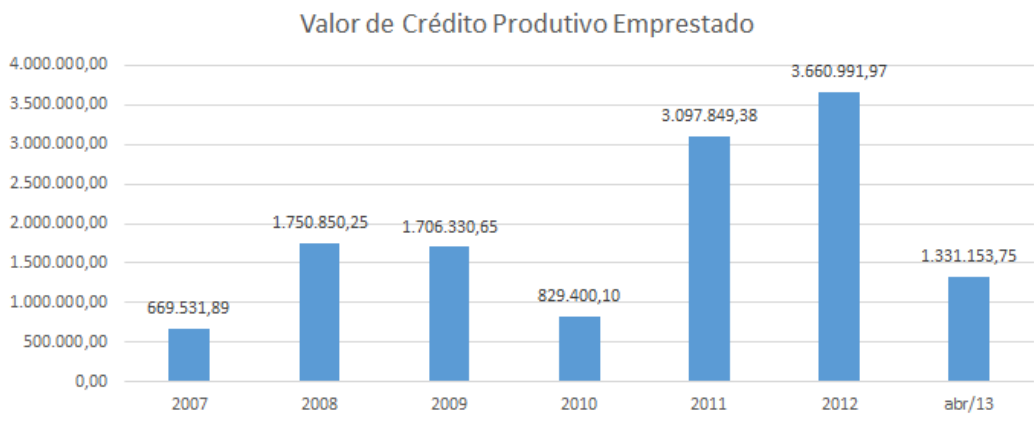

FONTE: Site Banco Palmas

No período de 2000 a 2010, como mostra o quadro 2 (Fonte: atlasbrasil.org.br), houve uma importante redução no quesito vulnerabilidade social na comunidade Conjunto Palmeiras. A porcentagem de vulneráveis à pobreza saiu de $80,92 \%$ para $64,13 \%$. Houve uma baixa na porcentagem de crianças extremamente pobres, saindo de $29,40 \%$ para $14,96 \%$, bem como melhoraram as condições de moradia com banheiro e água encanada da população da comunidade, saindo de 73,29\% para 95,35\%. Ou seja, os dados mostram que desde a fundação do Banco Palmas, em 1998, até 2010, só observou-se melhoras na condição de vida populacional.

QUADro 2 - Vulnerabilidade Social - UDH - Conjunto Palmeiras I - CE

\begin{tabular}{|c|c|c|}
\hline Crianças e Jovens & 2000 & 2010 \\
\hline Mortalidade infantil & 42,80 & 31,60 \\
\hline$\%$ de crianças de 0 a 5 anos fora da escola & 73,98 & 60,37 \\
\hline$\%$ de orianças de 6 a 14 fora da escola & 9,01 & 13,59 \\
\hline \% de pessoas de 15 a 24 anos que nāo estudam, não trabalham e sāo vulneráveis, na populaçāo dessa faixa & 26,23 & 30,37 \\
\hline$\%$ de mulheres de 10 a 17 anos que tiveram filhos & 7,41 & 2,87 \\
\hline Taxa de atividade - 10 a 14 anos & 4,26 & 9,65 \\
\hline \multicolumn{3}{|l|}{ Familia } \\
\hline \% de mães chefes de família sem fundamental $\theta$ com filho menor, no total de māes chefes de família & 83,53 & 63,72 \\
\hline \% de vulneráveis e dependentes de idosos & 3,90 & 1,77 \\
\hline$\%$ de crianças extremamente pobres & 29,40 & 14,96 \\
\hline \multicolumn{3}{|l|}{ Trabalho e Renda } \\
\hline \% de vulneráveis à pobreza & 80,92 & 64,13 \\
\hline \% de pessoas de 18 anos ou mais sem fundamental completo $\theta$ em ocupação informal & 59,15 & 52,49 \\
\hline \multicolumn{3}{|l|}{ Condição de Moradia } \\
\hline \% da populaçāo em domi & 73,29 & 95,35 \\
\hline
\end{tabular}

FONTE: PNUD, Ipea, FJP

Em 2010, a taxa de atividade, como mostra o gráfico 2, da população de 18 anos ou mais era de $52,80 \%$, ou seja, mais da metade dessa população estudada sendo economicamente ativa.

GRÁFICO 2 - Trabalho - Composição da População de 18 anos ou mais de idade - 2010
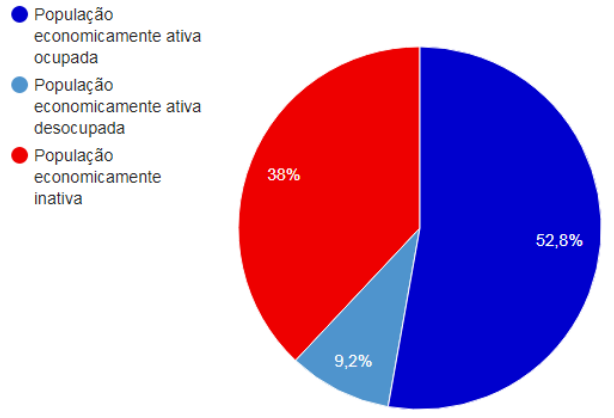

FONTE: PNUD, Ipea, FJP 


\section{CONSIDERAÇÕES FINAIS}

Diante do exposto, pode-se tecer aqui algumas reflexões sobre como o Microcrédito, objeto de estudo deste artigo, surgido a partir da necessidade latente de uma massa de indivíduos da sociedade moderna marginalizada e utilizado como ferramenta de geração de renda e serviços pelos bancos de desenvolvimentos, trouxe desenvolvimento para as localidades onde foram implantados.

Os BCDs em comunidades pobres, criados pela união solidária dos moradores, como forma de garantir microcréditos aos que não dispunham dos meios formais de garantias, trouxeram a possibilidade e a esperança de melhores condições de trabalho e consequentemente, de condições de vida a essa faixa da sociedade.

Observando os dados do gráfico 2 e do quadro 2, pode-se constatar um aumento na qualidade de vida e desenvolvimento até 2010 ocorrido na Comunidade Palmeiras, através do Censo coletado naquele ano e utilizado pelo site Atlas. Se considerarmos que é a partir de 2011, que os valores de crédito oferecidos pelo Banco Palmas voltam a crescer de forma vertiginosa até 2013, período da coleta, conforme demonstra o gráfico 1, podemos afirmar que, caso os números continuem crescendo nesta mesma proporção, o próximo censo de 2020 trará ainda mais índices melhores de desenvolvimento local.

Este artigo concluiu que o Microcrédito, através dos Bancos Comunitários de Desenvolvimento, vem como uma alternativa econômica eficaz. De fato, trata-se de uma mudança de cultura, onde se abre espaço para aqueles que não têm oportunidade no mercado, em virtude dos fatores desencadeados pelo surgimento do industrialismo, do capitalismo e da globalização, mas possuem o talento e a força de vontade de empreender. $\mathrm{O}$ desenvolvimento local não só dependerá dos grandes empresários, mas também dos pequenos como alternativa de crescimento e geração de renda.

Comparando os números dos índices de crescimento demonstrados, podemos afirmar que o oferecimento de créditos, na modalidade Microcrédito, às pessoas de baixa renda tem uma relação direta com o desenvolvimento da comunidade a qual essas pessoas estão inseridas. O exemplo do Conjunto Palmeiras nos remete aos pensamentos do célebre Professor Muhammad Yunnus que diz em suas palestras que a pobreza não precisa existir e que, se todos se juntarem nesse projeto, poderá existir sua erradicação.“...E aí existirão os museus da pobreza” (Muhammad Yunnus). 


\section{REFERÊNCIAS}

Banco Central do Brasil. Relatório de inclusão

financeira. - N. 2-. -. Brasília : BCB, 2011 - n. ; 29,7 cm. Disponível em: <https://www.bcb.gov.br/Nor/relincfin/ RIF2011.pdf $\geqslant$, acesso em 11 de setembro de 2018.

Banco Palmas 15 anos: resistindo e inovando / Núcleo de Economia Solidária - NESOL-USP e Instituto Palmas - São Paulo: A9 Editora, 2013. p. 29. Disponível em: <http://www. institutobancopalmas.org/wpcontent/uploads/LIVRO_BANCO_ PALMAS_15_ANOS.pdf $>$, acesso em 24 de setembro de 2018.

BARONE, Francisco Marcelo e SADER, Emir. Acesso ao crédito no Brasil: evolução e perspectivas.Rev. Adm. Pública [online]. 2008, vol.42, n.6, pp.1249-1267. ISSN o0347612. Disponível em: <http://dx.doi.org/10.1590/Soo3476122008000600012.>, acesso em 17 de setembro de 2018.

BRASIL.LEI № 13.636 DE 20 DE MARÇO DE 2018. IPI incidente sobre os produtos que menciona. Disponível em $<$ http://www.planalto.gov.br/ccivil_03/_ato2015-2018/2018/ Lei/L13636.htm>, acesso em 11 de setembro de 2018.

CARMONA, Charles Ulises De Montreuil e REZENDE, Argerlânia. Sustentabilidade dos Projetos dos microempreendedores: Uma Análise das principais garantias utilizadas nas operações de microcrédito e seus efeitos na redução do risco de crédito. 2013. Disponível em:<http://repositorio.uninove.br/xmlui/ bitstream/handle/123456789/493/607-1091-1-RV\%20 SUSTENTABILIDADE\%20DOS\%20PROJETOS\%2oDOS. pdf? sequence $=1>$, acesso em 26 de setembro de 2018 .

COSTA, F. N. Microcrédito no Brasil. Texto para Discussão. IE/UNICAMP, Campinas.

DANTAS, Valdi de Araújo. A Tecnologia do Microcrédito Produtivo e Orientado. Diponível em: $<$ http://www. mobilizadores.org.br/wp-content/uploads/2014/o5/texto5363c71a1c412.pdf $>$, acesso em 20 de setembro de 218 .

DOWBOR, L. Democracia Econômica. Edição revista e atualizada, julho de 2012, 131 p.

FILHO, Jaime Albuquerque Silveira. Microcrédito na Região Metropolitana do Recife: Experiência Empreendedora do CEAPE. ( Mestrado em Economia)- Universidade Federal de Pernambuco. Recife, 2005. Disponível em: $<$ https://repositorio.ufpe.br/bitstream/123456789/4355/1/ arquivo5967_1.pdf $>$, acesso em 20 de setembro 2018. 
MICROCRÉDITO. Características do Microcrédito. Disponível em: $<$ https://microcredito.wordpress.com/caracteristicasdo-microcredito/ $>$, acesso em 18 de setembro de 2018 .

MORAES, Erika Campanharo de; NOGUEIRA, Arnaldo Mazzei; VIEIRA, Regina Maria da Luz. Banco Grameen e Bancos Comunitários de Desenvolvimento: Uma Análise Comparativa. RISUS - Journal on Innovation and Sustainability Volume 6, número 3-2015. Disponível em: <https://revistas.pucsp.br/index.php/risus/article/ viewFile/20381/19164>, acesso em 11 de setembro de 2018 .

SOARES, Marden Marques. Microfinanças: o papel do Banco Central do Brasil e a importância do cooperativismo de crédito / Marden Marques Soares, Abelardo Duarte de Melo Sobrinho. - Brasília : BCB, 2008. 202 p. Disponível em: <https://www.bcb. gov.br/htms/public/microcredito/livro_microfinan $\% \mathrm{C}_{3} \% \mathrm{~A}$ 7as_ internet.pdf $>$, acesso em 18 de setembro de 2018 .

SENADO FEDERAL. Projeto de lei 13.636/2018. Sancionada lei para assegurar empréstimos a microempreendedores. Diponivel em: <https://www12.senado.leg.br/noticias/ materias/2018/03/21/sancionada-lei-para-assegurar-emprestimosa-microempreendedores $>$, acesso em 11 de setembro de 2018 .

SOUZA, Natália de Olivindo. Papel Estratégico do agente de crédito para a sustentabilidade do microcrédito produtivo orientado: O caso CredAmigo (BNB). Dissertação (Mestrado em Economia Aplicada)- Universidade Federal de Alagoas. Maceió, 2018. Disponível em: <http://www.repositorio.ufal. br/bitstream/riufal/2996/1/Papel\%2oestrat\%C3\%Aggico\%20 do\%2oagente $\% 20$ de $\% 20 \mathrm{cr} \% \mathrm{C}_{3} \%$ Agdito\%2opara\%20a\%20 sustentabilidade $\% 20$ do $\% 20$ microcr $\% C_{3} \%$ Agdito $\% 20$ produtivo\%2oorientado.pdf $>$, acesso em 25 de setembro de 2018 .

YUNUS NEGÓCIOS SOCIAIS. Muhammad Yunus. Disponível em: <https://www.yunusnegociossociais.com/ muhammad-yunus $>$, acesso em 11 de setembro de 2018. 